\title{
Exploring an Unfamiliar Space Reflections on the Socio-Psychological Aspects of Synchronous Online Teaching
}

\section{Andrea Ochsner}

Department of Economics, University of Applied Sciences Northwestern Switzerland, Switzerland.

\begin{abstract}
Online technologies provide a myriad of new teaching and learning methods, and while those new technologies have a lot of advantages, the rapid change from face-to-face to online teaching and distance learning during the COVID19 pandemic has made certain disadvantages visible, too. This paper focuses on the psychological impact of online learning on students, specifically in connection with the move from a well-known place, the university campus, to an unknown space, the online classroom. It explores why uncertainty and anxiety can result in reluctance to engage, a process that is caused by a lack of social information, low peer bonding possibilities and obstacles to create a sense of belonging. The findings are based on a general, theoretical understanding of psychological aspects that impact the virtual classroom, as well as on observations made during the lockdown period and its subsequent months of online teaching, drawing on concepts from social psychology, i.e. social cognition, social perception and conformity. What has become undoubtedly evident is that while the new technologies create new and creative spaces for teaching and learning, they are by no means free of stress and anxiety.
\end{abstract}

Keywords: Synchronous online teaching; social psychology; social cognition; social perception; conformity; place; space; sense of belonging; peer bonding. 


\section{Introduction}

Online courses have vastly gained in popularity in recent years, and consequently, a lot of academic articles have been published on their benefits (e.g. Montelongo 2019), challenges (e.g. Davis et al, 2019; Khan et al, 2017; Paudel 2021) and possible pitfalls (e.g. Dumford \& Miller 2018; Scherer \& Hatlevik 2017).

Whereas the new technologies offer a lot of innovative and creative potential, it has also come to light that a mere transposition of course contents from the lecture hall to the virtual classroom is not satisfactory at all, especially in connection with the COVID-19 pandemic that forced (tertiary) educational institutions to switch from on-site to online teaching at very short notice. Digitisation has made it possible for such a swift changeover to take place at all, and it has certainly provided a valid alternative to on-site teaching under the circumstances. Furthermore, online teaching and learning has increasingly been implemented even before the outbreak of the pandemic as more and more students rely on flexible modes of studying because it frees them from fixed timetables and locations and therefore allows for independence in terms of both place and time. Yet despite its benefits, the digitalised everyday also clearly shows its limits.

The sudden change to online teaching and learning has raised a lot of methodological and pedagogical questions as the drastic remodelling of context and medium has had a huge impact on how students can be taught, supported and assessed. However, whereas most of the discussions have centred around questions of contents and the manageability thereof, the psychological factors exercising an incisive and sometimes detrimental effect on students have been conspicuously few in number (Akpinar 2021; Sundarasen et al 2020). It is important not to neglect the human perspective because the changeover from face-to-face to online teaching also has far-reaching psychological consequences and can result in insecurity, anxiety and even depression. Classroom community, peer bonding and a sense of belonging (Vayre \& Vonthron 2017: 203, Dumford \& Miller 2018: 459) are just as important in the virtual classroom as on campus, probably even more so.

Therefore, this paper seeks to address those factors which have a psychological impact on students, particularly in a synchronous online teaching context. Specifically, I will argue that three concepts of social psychology might help pin down the possible reasons for students' anxiety and reluctance to actively participate in synchronous online classes. My theoretical approach is based on the belief that online learning requires a safe and empathic social space that needs to be established in the absence of the familiarity that more traditional learning spaces (and places) usually provide.

My exploration is divided into three parts. First, I will elucidate why familiar places play a role in how people conceptualise contexts, in our case a context of learning, and associate those places with mental structures and habitual practices humans need to make sense of their 
social world. In order to explain this specific correlation, I am going to draw on the concept of social cognition and schemas. Secondly, I will discuss how nonverbal communication is affected in the context of synchronous teaching and learning by making use of the theory of social perception, arguing that online communication does not really allow for nonverbal communication, which has a negative impact on self-assurance. In a third step, I am going to explore the relation between social influence and conformity prevalent in online classrooms.

\section{From place to space - lack of established schemas}

Place and space are often used synonymously, and while in certain contexts that may well be appropriate, the terms also have some distinguishing features. Some scholars claim that space is more abstract than place (Ellis \& Goodyear 2016); a building that one knows is more likely to be called a place than a space. It therefore also follows that a place is familiar and evokes security. In an educational context, the familiarity of the university campus, the library, the cafeteria, the lecture hall, etc. contribute to that sense of familiarity and hence security and a sense of belonging. In contrast, the virtual classroom is a space, not a place, and while it offers a whole lot of new possibilities due to its innovative potential, it may also cause insecurity due to being new, intangible and obscure. It is therefore crucial that, as Ellis and Goodyear (2016: 150) put it, "to find ways of understanding learning spaces such that they can be managed efficiently, for a common good, without damaging the subtle processes of local, dynamic reconfiguration and habitation that help students and teachers make 'likely places' for learning."

People are social beings and need contact. This contact is given structurally by the teaching situation. Apart from the presence during the lessons, other aspects also play an important role. The walk to the lecture hall, the usual way across the corridor, the coffee just before the lecture starts, the chat with peers on the stairs, the smell and noise level of the building - all those things fall away. The spatial environment of the campus with all its visual, auditory and olfactory characteristics is non-existent in online teaching. We do not walk a building, nor do we congregate in a physical room as the room we are actually sitting in, is not shared by others. From the lecturer's perspective the students do not wait in a lecture hall, but in their private study, living room or kitchen. The spontaneous opportunity to clarify an urgent question shortly before or after class is eliminated, and even the larger concerns tending to be articulated in a live classroom context, do not always find the perfect ear, either not being voiced at all or simply drowned in the tinny surroundings of the online learning platform such as for example Zoom. There is no opportunity for informal chats just before a lesson; likewise, icebreakers at the beginning of a session pose a problem, too. In a traditional classroom situation, students may be welcomed individually as they drop in - in an online session this is far more difficult and socially challenging as the constant signalling of people logging on makes this kind of informal welcoming ritual almost impossible. Furthermore, 
students often feel slightly anxious or even embarrassed when they first join a virtual session and hence do not react favourably to being called upon. What makes this sort of exchange even more difficult is the fact that most students do not feel comfortable entering the room with their camera switched on, a problem we shall consider in more detail in section three. In short, the whole sequence of arrival, settling in and being made welcome is rather different, and if not handled tactfully by the lecturer in charge, rather uncomfortably absent.

People are also creatures of habit. We associate certain surroundings with certain impending activities. Our brain tracks have stored these rituals coupled with their associations and thus guarantee a smooth and successful course for the required activities, which makes us feel safe. In order to perform these activities in a new, unfamiliar environment, our brain must first adapt and form new pathways. This does not happen from one day to the next and can therefore cause quite a bit of disorientation and insecurity. In social psychology, these associations are called schemas. Schemas are a blueprint according to which we behave and perform tasks in recurring situations. In other words, schemas are structures of thoughts and behaviour endowed with specific expectations and reactional patterns to them. Schemas are an important concept of the field of social cognition (the study of how people think about themselves and the social world) within social psychology (Bartlett 1932). We have schemas for commonly frequented places such as the supermarket, the dentist or the airport. In an educational context, schemas denote openly or (tacitly) agreed procedures, i.e. a certain way to go about things, and an orderly sequence of actions. Schemas are established over time and are triggered by contextual cues. If these are eliminated, we feel insecure since we have to construct new ones in order to rearrange our social reality and develop new mental processes that help us navigate new, emerging situations and spaces. In short, those schemas may not have been sufficiently established in the rather novel online teaching context, a reason why students find it difficult to orient themselves.

\section{From community to isolation - lack of attribution cues}

Another problem is nonverbal communication. Nonverbal communication helps people gather social information and interpret situations. In other words, it plays a major role in how we perceive our social space and our fellow human beings. Nonverbal communication includes gestures, posture, facial expression and eye contact. The latter is a vital source to make certain we are being acknowledged and listened to, and in the absence of other cues getting lost in the virtual space, actually play an even more important role in synchronous, online communication. It is, however, natural to make eye contact by directly looking at the person opposite, which does not work in front of a screen with a camera, because in order for the person opposite to feel perceived, one has to look straight into the camera and not at the person on the screen. Therefore, online eye contact is made indirectly, which takes some time and practice getting used to. Furthermore, eye contact is not only important between 
interlocutors, but also to get reassurance from other people in the room, especially peers, that one is on the right track as far as meaning-making processes are concerned. Students rely on eye contact, for example, to verify whether their questions are justified or whether they might be the only ones having difficulties to follow their lecturer's explanations. It is a vital social tool to create a sense of security, community and belonging. In the virtual classroom, however, this direct, non-verbal communication is not available to them, which has a negative effect on self-assurance and also negatively impacts student engagement.

Nonverbal behaviour is a vital part of what social psychologists call social perception, the study of how human beings form impressions and make deductions about other people. Once nonverbal communication cues have been interpreted, we make a connection between our interpretation and the person who provided us with nonverbal cues. This is called attribution, which is an unconscious, automatic process our brain performs in order to avail us with the necessary information we need to read a social situation and our role in it. If vital cues get lost in the virtual space, this process does not kick in, which may cause anxiety and stress because neither self-assurance nor a sense of belonging develop without the appropriate information that facilitates social perception in terms of making attributions and, ultimately, sense of other people.

Nonverbal communication actually makes up about $90 \%$ of human communication whereas verbal communication plays a rather minor part. In online communication, however, verbal communication becomes, rather unnaturally, far more important. Online communication makes people more polite, which in itself is not such a negative thing, but it is also rather artificial. People are constantly apologising for interrupting each other. In 'ordinary' communication, there is often a brief overlap as one speaker ends an utterance and another begins. This overlap is rather natural because we are used to the prosodic contours and the rhythms of speech and therefore we can successfully anticipate when an utterance comes to an end. In online communication, natural speech is disrupted because of the slight time lag occurring between utterances, which, as a consequence, makes the natural overlap sound disruptive. In other words, natural human communication does not work in videoconferencing as those tools are made for a single speaker at a time, which again, has a negative impact on attribution processes and ultimately, on the possibility of peer bonding.

\section{From individualism to conformity - lack of social information}

As we have seen above, the virtual classroom deprives students of a number of important cues in terms of social cognition and social perception. The third issue we deem important in this context concern these missing cues that result in insufficient social information and in a sort of passive conformity. Conformity is another key concept in social psychology and describes the change in one's behaviour due to the real or imagined influence of other people. 
The concept gained widespread recognition with the publication of Asch's and Milgram's seminal conformity experiments in the 1950s and 1970s (Asch 1951; Milgram 1974). The results of those experiments indicate that people use each other as a source of information in the sense that they base their judgment on what they perceive to be the majority's opinion about something. This happens either by private acceptance, i.e. they truly believe that their first conclusion may have been wrong and everybody else must be right, or by privately maintaining that their initial reaction to a problem was indeed right but conform to the majority's opinion, nonetheless. Apparently, this is especially true if the situation is ambiguous (Renfrow \& Gosling 2006). In short, when in a confusing situation and unsure what to do, people tend to rely on other people to help them define the situation and model their behaviour based on other people's.

Ambiguity very aptly describes the virtual classroom; there is a lot of ambiguity because of the missing schemas and the lack of nonverbal cues as discussed in the previous sections, which at least partly explains why students' engagement is often a problem in synchronous teaching settings. The term 'presence' has acquired a rather different meaning because one is never quite sure who is actually there as rather a lot of students are just logged in without making themselves visible, i.e. lurk anonymously without exposing themselves or adjusting their microphone and camera. It is rather astounding how many of the so-called digital natives have a hard time with online teaching. They prefer to consume passively and are very reluctant to make themselves visible - the anonymity of the Internet is thus transferred to the virtual classroom. This is, however, not really their fault. Just because they grew up using the Internet does not mean that they are willing to embrace all the possibilities it offers. The main attraction of the Internet for the Millennials is that it offers anonymity, and that they can quickly access information and easily connect with peers through various channels, but it does not necessarily follow that they feel comfortable in an online lecture. Being anonymous may lower anxiety at times, but also impedes original, individual contributions and reduces the possibility to create a proper sense of belonging as "(it) takes away some of the knowledge of who is different from oneself in the course" (Dumford \& Miller 2016: 461). Being anonymous in an ambiguous environment, which the virtual space is by definition and the virtual classroom by extension, where one never really knows what the peers are truly thinking, makes it seem rather normal to resort to this sort of passive conformity and not to make oneself visible as others do not do it either. It does, however, hinder smooth interaction as well as the creation of a safe and secure space of learning.

\section{Conclusion}

The list of challenging consequences online teaching has on natural human interaction is by no means complete and should be tested and complimented by means of empirical assessment procedures to create valid insights and practicable future guidelines for synchronous online 
teaching. Furthermore, it would be interesting to investigate how different groups of students (age, gender, culture, social background etc.) deal with the challenges of online education. Here it must suffice to emphasize that by becoming more sensitive to the psychology of virtual spaces, we can at least make sense of those processes that are often neglected in online teaching research but have a great impact on students' engagement, sense of belonging and ultimately, their mental well-being. Online teaching is a great addition to traditional, live teaching. It provides the possibility to teach, support, and assess students remotely. However, despite all the opportunities the digital transformation offers, it will never replace proper, human contact. Or to speak with Yi-Fu Tuan (1977), one of the leading scholars in human geography and spatial theory: "Place is security, space is freedom: we are attached to the one and long for the other." As alluring as freedom may be, humans need attachment in equal measure.

\section{References}

Asch, S.E. (1951). Effects of group pressure upon the modification and distortion of judgment. Guetzkow, H. (ed.). Groups Leadership and Men. Pittsburgh: Carnegie Press, 76-92.

Akpinar, E. (2021). The effect of online learning on tertiary level students' mental health during Covid19 lockdown. The European Journal of Social Behavioural Sciences, Volume XXX. doi: 10.15405/ejsbs.288.

Bartlett, F.C. (1932). Remembering. Cambridge: Cambridge University Press.

Davis, N.L., Gough, M. \& Taylor, L.L. (2019). Online teaching: advantages, obstacles and tolls for getting it right. Journal of Teaching in Travel \& Tourism, 19(3), 256-263. doi: $10.1080 / 153220.2019 .1612313$.

Dumford, A.D. \& Miller, A.L. (2018). Online learning in higher education: exploring advantages and disadvantage for engagement. Journal of Computing in Higher Education, 30, 452-465. Doi: 10.1007/s12528-018-9179-7.

Ellis, R.A. \& Goodyear, P. (2016). Models of learning space, place and learning in higher education. Review of Education, 4(2), 149-191. Doi: 10.1002/rev3.3056.

Kelley, H.H. (1973). The Process of Causal Attribution. American Psychologist (28), 107128.

Khan, A., Egbue, O, Palkie, B. \& Madden, J. (2017). Active learning: Engaging students to maximize learning in an online course. The Electronic Journal of e-Learning, 15(2), 107155.

Milgram, S. (1974). Obedience to Authority: An Experimental View. New York: Harper \& Row.

Montelongo, R. (2019). Less than/more than: Issues associated with high-impact online teaching and learning. Administrative Issues Journal: Connecting Education, Practice, and Research, 9(1), 68-79. doi: 10.5929/9.1.5. 
Paudel, P. (2021). Online education: Benefits, challenges and strategies during and after COVID-19 in higher education. International Journal on Studies in Education, 3(2), 7085.

Renfrow, P.J. \& Gosling, S.D. (2006). Message in a ballad: The role of music preferences in interpersonal perception. Psychological Science (17), 236-242.

Scherer, R. \& Hatlevik O.E. (2017). 'Sore eyes and distracted' or 'excited and confident'? The role of perceived negative consequences of using ICT for perceived usefulness and self-efficacy. Computers \& Education, 115, 188-200.

Sundarasen, S. et al. (2020). Psychological impact of COVID-19 and lockdown among university students in malaysia: Implications and policy recommendations. International Journal of Environmental Research and Public Health, 17. doi: 10.3390/ijerph17176206.

Tuan, Y. (1977). Space and Place: The Perspective of Experience. Minneapolis: University of Minnesota Press.

Vayre, E. \& Vonthron, A.-M. (2017). Psychological engagement of students in distance and online learning: effects of self-efficacy and psychological processes. Journal of Educational Computing Research, 55(2), 197-218. doi: 10.1177/0735633116656849. 